Western University

Scholarship@Western

Human Environments Analysis Lab (HEAL)

$1-2020$

\title{
Assessing the effectiveness of a naturally occurring population- level physical activity intervention for children
}

\section{Smith}

Western University, chsmith@london.ca

\author{
A. F. Clark \\ Western University, aclark2@uwo.ca \\ P. Wilk \\ Western University, pwilk3@uwo.ca \\ P. Tucker \\ Western University, ttucker2@uwo.ca
}

J. A. Gilliland

Western University, jgillila@uwo.ca

Follow this and additional works at: https://ir.lib.uwo.ca/healpub

Citation of this paper:

Smith, C.; Clark, A. F.; Wilk, P.; Tucker, P.; and Gilliland, J. A., "Assessing the effectiveness of a naturally occurring population-level physical activity intervention for children" (2020). Human Environments Analysis Lab (HEAL). 2.

https://ir.lib.uwo.ca/healpub/2 


\title{
Original Research
}

\section{Assessing the effectiveness of a naturally occurring population-level physical activity intervention for children}

\author{
C. Smith ${ }^{a, b}$, A.F. Clark ${ }^{a, b}$, P. Wilk ${ }^{b, c}$, P. Tucker ${ }^{d}$, J.A. Gilliland ${ }^{b, e, *}$ \\ ${ }^{a}$ Human Environments Analysis Laboratory, Department of Geography, University of Western Ontario 1151 \\ Richmond St., London, N6A 3K7, Canada \\ b Children's Health Research Institute, 800 Commissioners Road East, London, N6C 2V5, Canada \\ ${ }^{\mathrm{c}}$ Department of Epidemiology \& Biostatistics, Department of Paediatrics, University of Western Ontario 1151 \\ Richmond St., London, N6A 3K7, Canada \\ d School of Occupational Therapy, University of Western Ontario 1151 Richmond St., London, N6A 3K7, Canada \\ e Human Environments Analysis Laboratory, Department of Geography, School of Health Studies, Department of \\ Epidemiology \& Biostatistics, Department of Paediatrics, University of Western Ontario 1151 Richmond St., London, \\ N6A 3K7, Canada
}

\section{A R T I C L E I N F O}

\section{Article history:}

Received 15 February 2019

Received in revised form

24 June 2019

Accepted 23 August 2019

Available online 14 October 2019

\section{Keywords:}

Recreation

Physical activity

Child health

Health promotion

Health behavior

\begin{abstract}
A B S T R A C T
Objectives: The aim of the study was to assess the impact of a recreation access pass on grade 5 children's physical activity (PA) levels.

Study design: This is a pre-post evaluation of a population-level community-based intervention.

Methods: All grade 5 students in (London, Ontario, Canada) were invited to participate in the [ACT-i-Pass] program (G5AP) in May 2014. A total of 643 children completed surveys, that included Physical Activity Questionnaire for Children (PAQ-C), at baseline (October 2014) and 6-month follow-up (April 2015). Difference in the means t-test compared PAQ-C scores between baseline and follow-up for the sample and subgroups. Multiple regression analysis tested associations between change in PAQ-C scores and intrapersonal-, interpersonal-, and physical environment-level variables.

Results: PA increased significantly from baseline to 6-month follow-up. Girls, visible minorities, immigrants, and children with low parental support experienced significant increases in PA. Regression found girls benefitted from the G5AP significantly more than boys, and lower parental support is related to increases in PA.

Conclusion: The findings indicate that collaboratively developed, community-based interventions can significantly increase children's PA levels, particularly among subgroups with traditionally lower PA. The pre-post evaluation of this community-based intervention
\end{abstract}

\footnotetext{
* Corresponding author. Children's Health Research Institute, 800 Commissioners Road East, London, N6C 2V5, Canada. Tel.: +1 519 661 2111x81239; fax: 15196613750.

E-mail addresses: chsmith@london.ca (C. Smith), aclark2@uwo.ca (A.F. Clark), pwilk3@uwo.ca (P. Wilk), ttucker2@uwo.ca (P. Tucker), jgillila@uwo.ca (J.A. Gilliland). 
provides useful evidence for developing policies and programs aimed at making population-level improvements in children's PA levels.

(C) 2019 The Royal Society for Public Health. Published by Elsevier Ltd. All rights reserved.

\section{Introduction}

Low physical activity (PA) levels among children are a concern in many countries. ${ }^{1,2}$ Various PA interventions with children and youth, such as coaching, educational, policy, and environmental, have been tested, with evaluations finding mixed results as to their effectiveness. ${ }^{3}$ Reviews examining the effectiveness of PA interventions have found limited efficacy for changing children's overall PA levels. ${ }^{3-5}$ Community-based PA interventions are the most effective approach owing to the potential to achieve population-level change in children's PA levels. ${ }^{6,7}$ To be most effective and sustainable, community-based interventions must involve cross-sector collaborations with community groups, academic institutions, recreation facilities, schools, and policy-makers. ${ }^{6,7}$ Cross-sector collaborations present a unique opportunity for program evaluation as they increase the likelihood of being able to examine naturally occurring interventions.

Given the focus on population-level change, a number of community-based PA interventions have been developed through the lens of the social ecological model to address a range of factors that contribute to PA. ${ }^{7,8}$ The social ecological model of health promotion proposes that a range of factors at multiple levels influence behaviors, including intrapersonal (i.e., gender, age, and attitudes), interpersonal (i.e., social support and household income), community, physical environment, and policy. ${ }^{7}$ The social ecological model is also useful to address how a place interacts with behavior by identifying the characteristics of places that facilitate or hinder PA. ${ }^{7,9}$ This study examines a city-wide initiative, the Grade 5 ACT-i-Pass program (G5AP) ${ }^{10,11}$ that was developed and initiated by London's Child \& Youth Network, a network of more than 170 local organizations focused on improving children's health and well-being. The G5AP offered all children in grade 5 who live or attend school in London, Ontario, a mid-sized Canadian city, a free recreational access pass to use at facilities (e.g., YMCA, Boys and Girls Club of London, arenas, pools) and for programs (e.g., drop-in programs, dance, soccer, and basketball) across the city between September and June of the 2014-15 school year (see Fig. 1). The G5AP was designed to reduce financial barriers to access PA opportunities and increase parents' awareness of the resources that exist in the city. The purpose of this study was to assess the impact of the G5AP on PA levels of children, which is evaluated by addressing three objectives: to assess whether there was a change in PA between baseline and 6-month follow-up; to examine change in PA across different subgroups of children; and to investigate how intrapersonal, interpersonal, and physical environment characteristics predict change in children's PA.

\section{Methods}

This study is a pre-post evaluation of a naturally occurring population-level intervention designed to examine how the G5AP changes PA behavior over time. A full description of the research can be found elsewhere, ${ }^{10,11}$, and a diagram of the research process is in Fig. 2. The G5AP intervention was offered to all grade 5 children who live or attend school in the City of London, Ontario, with the principals of 98 of the 99 schools in the city allowing their students to participate in the research. All grade 5 children attending the 98 schools were invited to participate in the study through the registration form sent home to parents. This invitation included an opportunity for the parents to complete a survey and provide informed consent for their child to complete surveys throughout the study period. Research participation was not mandatory to receive the G5AP. Once parental consent was received, the assent form was reviewed with the students, and they provided their own assent.

Data collection occurred in 2014-2015 and involved three self-report parent surveys and four child surveys, which were administered at baseline, 1 month after receiving the G5AP, 6 months after receiving the G5AP, and 4 months after the G5AP ended. This specific study used baseline parent survey and two child surveys collected at baseline and 6 months after receiving the G5AP (follow-up survey). The baseline child survey provided sociodemographics (i.e., age, gender, and family composition) and parental and peer support for PA. The Physical Activity Questionnaire for Children (PAQ-C), embedded in all child surveys, is a self-administered 7-day recall measuring general PA. ${ }^{12}$ The baseline parent survey collected sociodemographic data that a child may not know (i.e., ethnicity, immigrant status, parental education level, parental employment status, and household income) and home postal code.

\section{Sample}

As described in Fig. 2, a total of 1709 children of 3677 eligible children across 98 schools registered for the G5AP. Of the 1709 registrants, 957 participated in the study and completed baseline surveys (56.0\% response rate), and 896 participants completed the 6-month follow-up survey $(93.7 \%$ retention rate). Participants were excluded from analysis if they did not have complete PA outcome data at both timepoints, resulting in a final sample size of 643 participants with matched pairs of data between baseline and 6-month follow-up. 


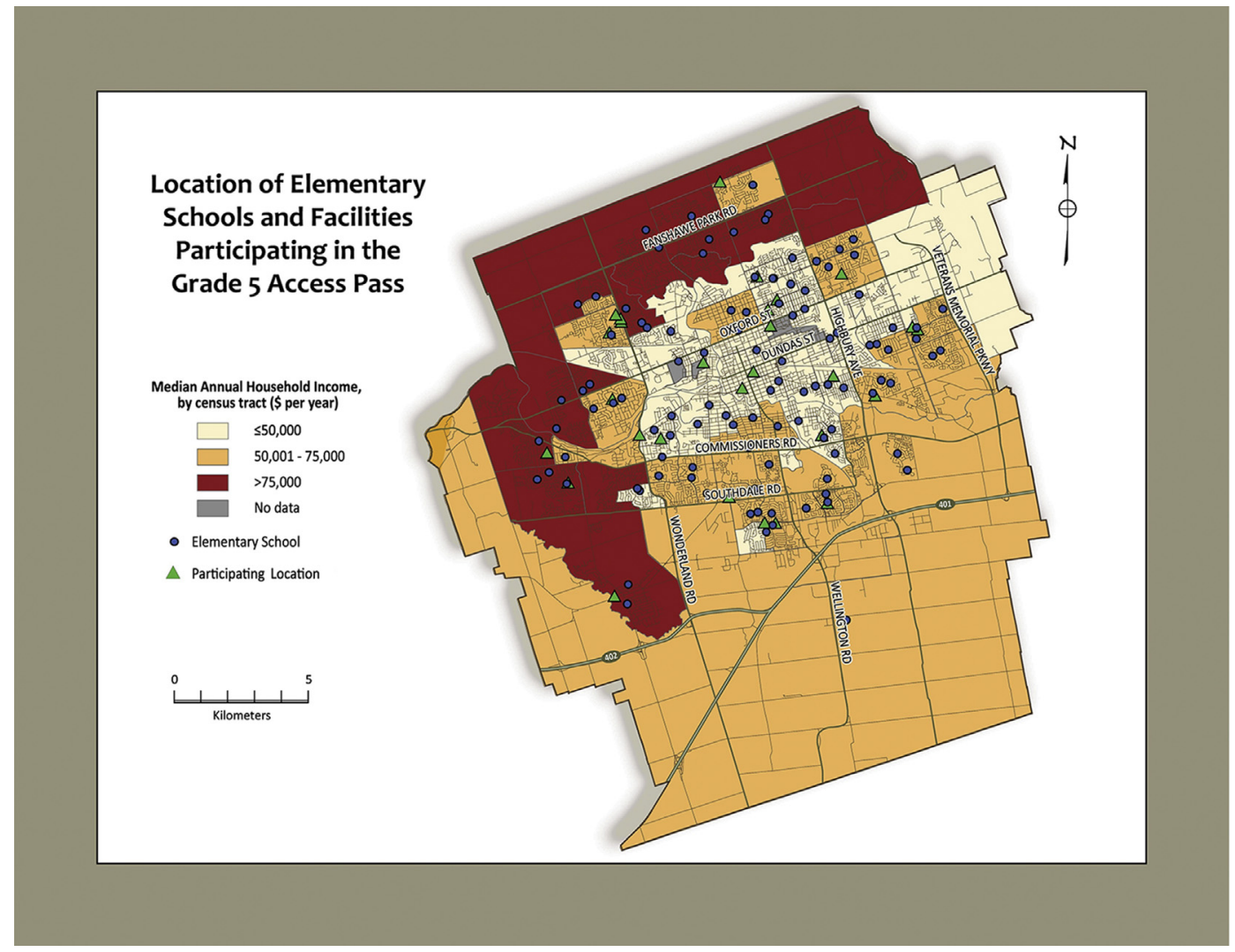

Fig. 1 - Location of elementary schools and facilities participating in the G5AP program reproduced from Gilliland et al. ${ }^{10}$.

\section{Measures}

Outcome measure: general PA levels

PA was measured using the PAQ-C, which consists of 9 items scored on a 5-point Likert scale, with higher values indicating greater levels of PA. ${ }^{12}$ Items assessed different aspects of PA, such as spare time activity, average weekly PA levels, and context-specific activity. PAQ-C scores were computed for each child at baseline and the 6-month follow-up. ${ }^{12}$ The final PAQ-C activity summary score represents general PA levels. Previous studies show the PAQ-C is a reliable and valid selfreport measure for school-age children (grades $4-8) .^{12,13}$ The dependent variable is the difference between baseline and the follow-up PAQ-C activity score, where a positive value represents an increase in PA (and negative, a decrease).

\section{Independent variables}

Using the social ecological model as a guiding framework, ${ }^{7,8}$ multiple levels (intrapersonal, interpersonal, and physical environment) of independent variables were included to examine potential influences on change in PA. Intrapersonallevel variables control for differences in demographic characteristics that previous studies have shown to influence PA levels: gender (boy or girl), visible minority (white/Caucasian or other ethnicities), and immigrant status (born in Canada or born elsewhere). ${ }^{14-18}$

Interpersonal-level variables are used to examine how the social environment influences PA levels. Lone-parent (two parents or lone-parent), parental education level for the mother and father (high school graduate or less or at least college/university), and full-time employment status for the mother and father (not full-time or full-time) are used as a measure of household socio-economic status. Median household income (CAD) was used as a proxy measure of neighborhood socioeconomic status. Data were obtained from the 2011 Census of Canada and measured for the dissemination area (DA) corresponding to each child's postal code. A DA typically covers one or more city blocks with an approximate population between 400 and 700 people. ${ }^{19}$ Prior research indicates that neighborhood-level income is a valid proxy for household income in population studies. $^{20}$

Child perceptions of parental and peer support impacting PA levels are also used to see how social supports relate to change in PA. ${ }^{21}$ Parental support was measured by averaging the responses on a 5-point scale ranging from never (1) to daily (5) for four questions about the frequency a child's parent encourages him/her to play, provides transportation to PA opportunities, watches the child participate in activities, and actively engages in PA with the child. ${ }^{15}$ Peer support was measured by averaging the responses using the same 5point scale to questions about the frequency a child's peers/ friends encourage PA, play with the child, tease the child about PA (reverse-coded), and praise the child about PA. ${ }^{22}$ The final measures are a score between 1 and 5 (low to high support). ${ }^{23}$ 
All schools in the City of London were invited to participate in the G5AP project $(n=99)$

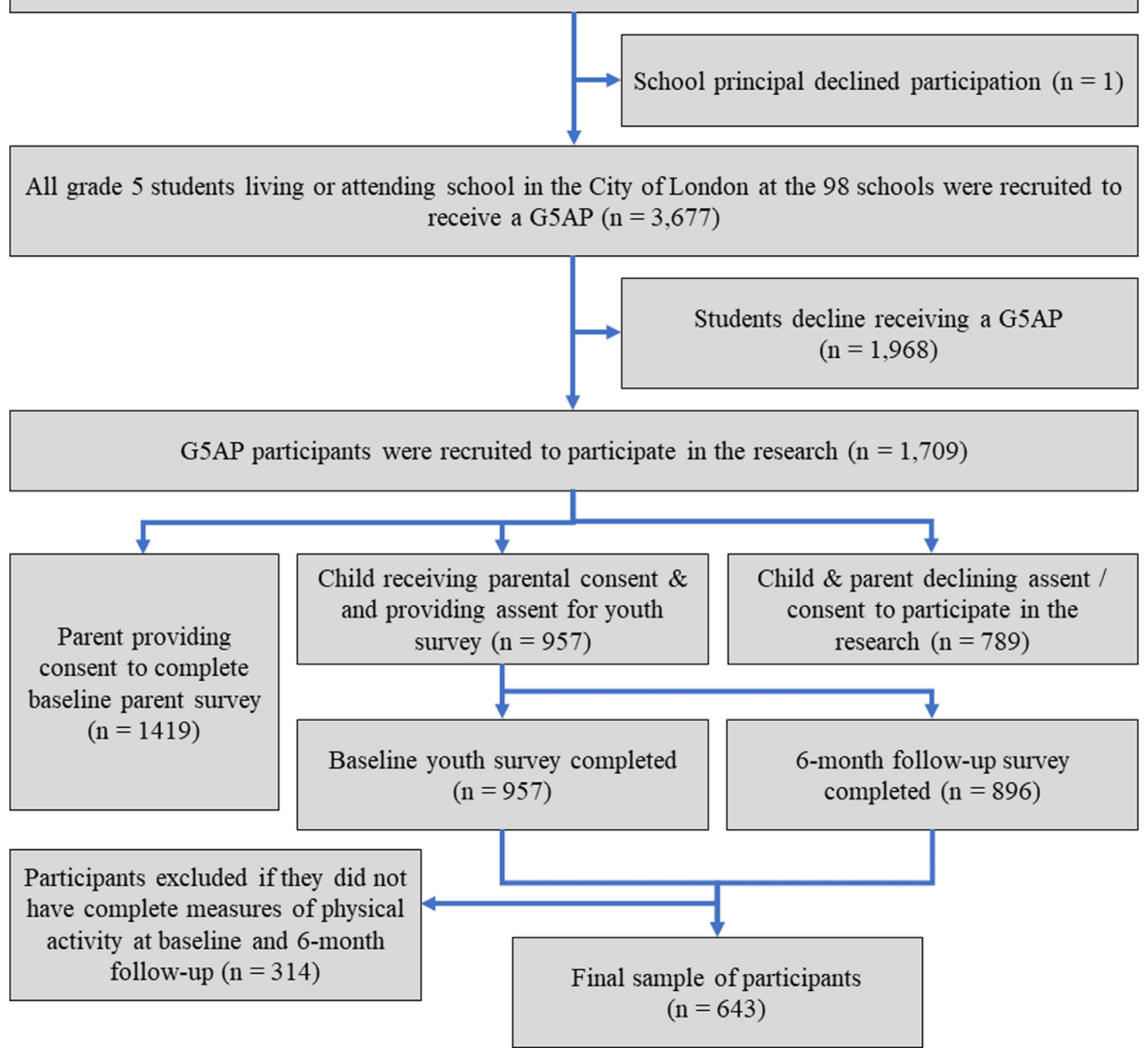

Fig. 2 - Flow diagram of the progress through the phases of a naturally occurring pre-post population-level intervention study, including uptake, recruitment, intervention, follow-up, and data analysis.

Physical environment variables include geographic accessibility as computed using ArcMap 10.3 (Environmental Systems Research Institute, Redlands, CA) using the Network Analyst tool, which is the shortest distance (along the street network) between a child's home postal code and the closest recreation facility by type that are part of the G5AP program. Measured facility types include YMCA (3 locations), Boys and Girls Club (1 location), arenas (10 locations), and pools (3 locations).

\section{Statistical analyses}

Statistical analyses were performed using STATA SE 14 (StataCorp LLC, College Station, TX). Difference in self-reported PA levels from 6-month follow-up and baseline difference between subgroups of children was examined using paired t-tests, which include all intrapersonal-, interpersonal-, and physical environment-level independent variables. Multiple regression analysis was used to test the association between change in PA and intrapersonal-, interpersonal-, and physical environment- 
level variables (see Table 3). Model 1 included the entire sample $(n=643)$ with robust standard errors. Additional models were stratified by gender (model 2: boys, model 3: girls), given the evidence on the relationship between gender and PA. ${ }^{1,14,24}$

\section{Results}

\section{Characteristics of the sample}

As seen in Table 1, of the 643 participants, $48.7 \%$ were boys and $51.3 \%$ were girls. The mean age of participants was 9.8 years (standard deviation $[S D]=0.57$ ) at baseline. A majority of participants were born in Canada (90.1\%) and were not a visible minority (68.7\%). Most participants had a sibling (92.2\%), lived in a two-parent household (80.9\%), and had at least one car at home (93.4\%). The parents were highly educated, with $70.6 \%$ of fathers and $81.5 \%$ of mothers having achieved at least college or university level of education; in addition, $77.6 \%$ of fathers and $53.8 \%$ of mothers worked fulltime. The perceived social support was relatively high for both parental $(\mu=3.62, \mathrm{SD}=1.94)$ and peer support $(\mu=4.41$, $\mathrm{SD}=1.56)$. The median household income was $\$ 67,599$ (CAD), and the average distance to the closest G5AP recreation

\section{Table 1 - Characteristics of the study participants} $(n=643)$.

\begin{tabular}{lc} 
Variables & $\begin{array}{c}\text { Descriptive } \\
\text { statistics }\end{array}$ \\
\hline Intrapersonal-level & \\
Gender, $n$ (\%) & \\
Boy & $313(48.7)$ \\
Girl & $330(51.3)$ \\
Visible minority, $n$ (\%) & $201(31.3)$ \\
Born outside of Canada, $n$ (\%) & $64(9.9)$ \\
Interpersonal-level & \\
Siblings, $n$ (\%) & $593(92.2)$ \\
Live in lone-parent household, $n$ (\%) & $120(18.7)$ \\
Maternal education, $n$ (\%) & \\
High school or less & $107(16.6)$ \\
$\quad$ At least college/university & $524(81.5)$ \\
Paternal education, $n$ (\%) & \\
$\quad$ High school or less & $152(23.6)$ \\
At least college/university & $454(70.6)$ \\
Mother employed full-time, $n$ (\%) & $346(53.8)$ \\
Father employed full-time, $n$ (\%) & $499(77.6)$ \\
Car ownership, $n$ (\%) & \\
No car & $34(5.3)$ \\
1 car & $192(29.9)$ \\
2 or more & $408(63.5)$ \\
Median household income (10,000 CAD), & $6.75(2.55)$ \\
mean (SD) & \\
Parental support, mean (SD) & $3.62(1.94)$ \\
Peer support, mean (SD) & $4.41(1.56)$ \\
Physical environment-level & \\
Geographic accessibility to the closest... & \\
G5AP facility in km, mean (SD) & \\
YMCA facility in km, mean (SD) & $2.54(2.44)$ \\
Boys and Girls Club in km, mean (SD) & $5.45(3.29)$ \\
Arena in km, mean (SD) & $6.81(3.22)$ \\
Pool in km, mean (SD) & $3.08(2.6)$ \\
SD, standard deviation. & $4.97(2.96)$ \\
\hline & \\
\hline
\end{tabular}

facility was $2.54 \mathrm{~km}$. There were no significant differences between the 643 participants who completed the 6-month follow-up (study sample) and the total sample of 957 participants who completed baseline surveys.

\section{Average differences in self-reported PA}

As seen in Table 2, overall, PA increased significantly $(P<0.001)$ from baseline $(\mu=3.28, \mathrm{SD}=0.72)$ to 6 -month follow-up $(\mu=3.42, \mathrm{SD}=0.68)$. Although PA increased for both boys and girls from baseline to 6-month follow-up, this difference was only significant for girls $(P<0.001)$. Participants who were identified as visible minorities showed increase in their PA level significantly $(P<0.001)$ from baseline $(\mu=3.24$, $\mathrm{SD}=0.70)$ to 6 -month follow-up $(\mu=3.46, \mathrm{SD}=0.62)$, more than non-visible minorities $(P<0.001)$ from baseline $(\mu=3.30$, $\mathrm{SD}=0.73)$ to 6 -month follow-up $(\mu=3.40, \mathrm{SD}=0.71)$. Significant increases in PA were also found for children not born in Canada $(\mu=3.25$ increased to $3.49, P<0.001)$. Participants who reported low parental support at baseline significantly $(P<0.001)$ showed increased PA from baseline $(\mu=2.83$, $\mathrm{SD}=0.74)$ to 6 -month follow-up $(\mu=3.09, \mathrm{SD}=0.67)$. No significant differences were found for children from lone-parent households, those with less educated or underemployed fathers, and those with high parental and peer support.

\section{Factors relating to PA behavior change}

Table 3 shows the three models specified to assess the entire sample (model 1) and then stratified by gender (boys: model 2, girls: model 3$)$. In model 1 , gender $(\beta=0.14, P=0.010)$ and parental support $(\beta=-0.05, P<0.001)$ explained $5.8 \%$ of the variance in change in PA for the entire sample. Girls were found to have benefitted from the G5AP significantly more than boys. Parental support at baseline was negatively associated with change in PA, such that high parental support decreased change in PA. In addition, the results from genderstratified models indicate that only parental support significantly predicted change in PA for boys $(\beta=-0.06, P=0.010)$; however, this was a negative association. There were no significant predictors of change in PA for girls.

\section{Discussion}

The purpose of this study was to determine whether children's participation in a population-level intervention increased their PA level. The G5AP intervention was evaluated by assessing the differences in PA between baseline and 6month follow-up; examining associations among different subgroups of children; and investigating how multiple factors at different levels predicted change in children's PA. The G5AP sought to increase children's general PA levels by providing free access to PA facilities/programming throughout the community. Overall, the findings indicate that the G5AP significantly increased PA levels and demonstrate the effectiveness of this strategy for improving children's PA at the population level. Although the positive change in PA is encouraging, the incremental increase should be considered carefully as the sample of children already had a high PA score 
Table 2 - Average differences in self-reported PA from baseline to 6-month follow-up by demographic subgroups ( $n=643$ ).

\begin{tabular}{|c|c|c|c|c|c|}
\hline \multirow[t]{2}{*}{ Variables } & \multirow{2}{*}{$\frac{\text { Baseline }}{\text { Mean (SD) }}$} & \multirow{2}{*}{$\frac{6 \text {-month Follow-up }}{\text { Mean (SD) }}$} & \multirow{2}{*}{$\frac{\text { Difference }}{\text { Mean }}$} & \multicolumn{2}{|c|}{ Difference in the means tes } \\
\hline & & & & $\mathrm{t}$ & $P$ \\
\hline Total sample & $3.28(0.72)$ & $3.42(0.68)$ & 0.14 & -5.12 & $<0.00$ \\
\hline \multicolumn{6}{|l|}{ Intrapersonal-level } \\
\hline \multicolumn{6}{|l|}{ Gender } \\
\hline Boy & $3.36(0.72)$ & $3.42(0.71)$ & 0.06 & -1.41 & 0.16 \\
\hline Girl & $3.21(0.72)$ & $3.42(0.66)$ & 0.22 & -5.96 & $<0.00$ \\
\hline \multicolumn{6}{|l|}{ Visible minority } \\
\hline No & $3.30(0.73)$ & $3.40(0.71)$ & 0.10 & -3.14 & $<0.00$ \\
\hline Yes & $3.24(0.70)$ & $3.46(0.62)$ & 0.22 & -4.60 & $<0.00$ \\
\hline \multicolumn{6}{|l|}{ Born outside of Canada } \\
\hline No & $3.29(0.73)$ & $3.41(0.69)$ & 0.13 & -4.45 & $<0.00$ \\
\hline Yes & $3.25(0.65)$ & $3.49(0.61)$ & 0.25 & -2.85 & $<0.00$ \\
\hline \multicolumn{6}{|l|}{ Interpersonal-level } \\
\hline \multicolumn{6}{|l|}{ Live in lone-parent household } \\
\hline No & $3.29(0.70)$ & $3.43(0.67)$ & 0.15 & -5.00 & $<0.00$ \\
\hline Yes & $3.26(0.82)$ & $3.35(0.74)$ & 0.08 & -1.22 & 0.23 \\
\hline \multicolumn{6}{|l|}{ Maternal education } \\
\hline High school or less & $3.20(0.77)$ & $3.37(0.79)$ & 0.17 & -2.44 & 0.01 \\
\hline College/university or more & $3.29(0.71)$ & $3.42(0.66)$ & 0.13 & -4.44 & $<0.00$ \\
\hline \multicolumn{6}{|l|}{ Paternal education } \\
\hline High school or less & $3.37(0.79)$ & $3.47(0.72)$ & 0.11 & -1.74 & 0.08 \\
\hline College/university or more & $3.25(0.69)$ & $3.41(0.67)$ & 0.16 & -5.50 & $<0.00$ \\
\hline \multicolumn{6}{|l|}{ Mother employed full-time } \\
\hline No & $3.32(0.70)$ & $3.49(0.68)$ & 0.18 & -4.12 & $<0.00$ \\
\hline Yes & $3.24(0.73)$ & $3.36(0.66)$ & 0.11 & -3.13 & $<0.00$ \\
\hline \multicolumn{6}{|l|}{ Father employed full-time } \\
\hline No & $3.29(0.73)$ & $3.43(0.66)$ & 0.15 & -1.91 & 0.06 \\
\hline Yes & $3.28(0.71)$ & $3.41(0.68)$ & 0.13 & -4.38 & $<0.00$ \\
\hline \multicolumn{6}{|l|}{ Parental support } \\
\hline Low & $2.82(0.74)$ & $3.09(0.67)$ & 0.27 & -4.72 & $<0.00$ \\
\hline Average & $3.27(0.63)$ & $3.43(0.67)$ & 0.16 & -4.15 & $<0.00$ \\
\hline High & $3.72(0.61)$ & $3.70(0.58)$ & -0.02 & 0.33 & 0.75 \\
\hline \multicolumn{6}{|l|}{ Peer support } \\
\hline Low & $2.74(0.86)$ & $2.94(0.74)$ & 0.20 & -1.60 & 0.12 \\
\hline Average & $3.12(0.70)$ & $3.29(0.68)$ & 0.17 & -4.66 & $<0.00$ \\
\hline High & $3.61(0.60)$ & $3.69(0.59)$ & 0.08 & -1.90 & 0.06 \\
\hline \multicolumn{6}{|l|}{ Median household income } \\
\hline Low-income & $3.29(0.77)$ & $3.43(0.72)$ & 0.14 & -2.46 & 0.02 \\
\hline Medium-income & $3.29(0.70)$ & $3.39(0.68)$ & 0.10 & -2.02 & 0.05 \\
\hline High-income & $3.26(0.72)$ & $3.43(0.66)$ & 0.17 & -4.21 & $<0.00$ \\
\hline \multicolumn{6}{|l|}{ Physical environment-level } \\
\hline Recreation facility located $<1.6 \mathrm{~km}$ & $3.29(0.75)$ & $3.40(0.69)$ & 0.11 & -2.46 & 0.01 \\
\hline Recreation facility located $>=1.6 \mathrm{~km}$ & $3.27(0.71)$ & $3.43(0.68)$ & 0.15 & -4.51 & $<0.00$ \\
\hline
\end{tabular}

PA, physical activity; SD, standard deviation.

at baseline $(\mu=3.28, \mathrm{SD}=0.72) \cdot{ }^{12}$ Compared with several other studies that used the PAQ-C, our sample achieved a higher baseline score; however, none of these studies used the tool in an intervention setting. ${ }^{25-27}$ This suggests that selection bias may play a role in the results as children who were already physically active may have been more likely to seek out additional opportunities to be active. That said, although children were already very active before the intervention, it is encouraging that a significant increase in overall PA levels was observed from baseline to 6-month follow-up, particularly as this is an age when children's PA participation tends to sharply decline. ${ }^{1,16,17}$

Promising results were also found for certain subgroups of children. Previous research has consistently shown that girls achieve lower levels of PA than boys. It is therefore encouraging that girls participating in the intervention achieved significantly higher increases in PA, than boys. Baseline assessments indicate that girls had slightly lower PA scores than boys before the intervention and, therefore, had more room to increase. This increase may be linked to the play-based (i.e., drop-in programs, free swim, and free skate) and non-competitive activities (e.g. basketball skills, cheerleading, hip-hop dance, soccer, and volleyball) included as part of the G5AP, which have been shown to improve PA outcomes for girls. ${ }^{28,29}$ These findings emphasize the importance of gender differences in PA as research shows that girls prefer different types of PA than boys and have different motivations for engaging in PA. ${ }^{30}$

The impact of the G5AP among visible minority and foreign-born children is noteworthy. Previous research found that immigrant children were less likely to participate in 
organized PA than those who were born or have lived longer in a location. ${ }^{18}$ This was the case in our baseline data; however, we found that visible minorities and foreign-born children achieved improvements in PA over the intervention. Many population-based PA interventions have been found to increase health inequalities owing to the lack of targeted components; ${ }^{31}$ however, the G5AP program demonstrated significant increases in PA for these subgroups of children.

Our baseline assessments indicate that children from loneparent households had slightly lower PA scores than children from two-parent households before the intervention. After the G5AP intervention, we found that children from two-parent households experienced statistically significant increases in PA levels, whereas children from lone-parent households did not. Simply removing financial barriers to access PA opportunities at community facilities is not enough to increase PA behaviors in lone-parent households. This is supported by research that found children in lone-parent families experience additional barriers to PA besides economic barriers, such as competing demands placed on a single parent. ${ }^{32,33}$

Boys with low levels of perceived parental support for PA at baseline achieved significantly higher PA over the course of the intervention than those children with average and high levels of parental support. The G5AP program included a number of program offerings, multiple locations, and the ability to bring one guest for free. These additional program features may have increased parents' capacity to provide support for their child's PA. Our study found parental support to be negatively associated with change in PA, that is, children who reported higher levels of parental support for their PA actually experienced significant declines in their PA between baseline and follow-up. Studies have found a positive association between parental support and children's PA levels. ${ }^{34-36}$ As the data indicate, children with higher levels of parental support reported higher levels of PA at baseline, and it is possible that these well-supported children are already participating in enough organized PA activities that the G5AP would not have a positive impact on PA levels. Children's perception of parental support for the sample was above average (3.62), suggesting that a majority of participants felt supported by their parents in terms of PA. However, the score for parental support used a limited range (i.e., 5-point scale, 1: low support, 5: high support), and therefore, the variable could be subject to ceiling effects as there is little room for change.

These findings could be a limitation of the variables used to assess change in PA. Sallis et al. ${ }^{37}$ assessed predictors of

Table 3 - Results of full model and gender-stratified models assessing intrapersonal, interpersonal, and physical environment variables' influence of changes in general physical activity.

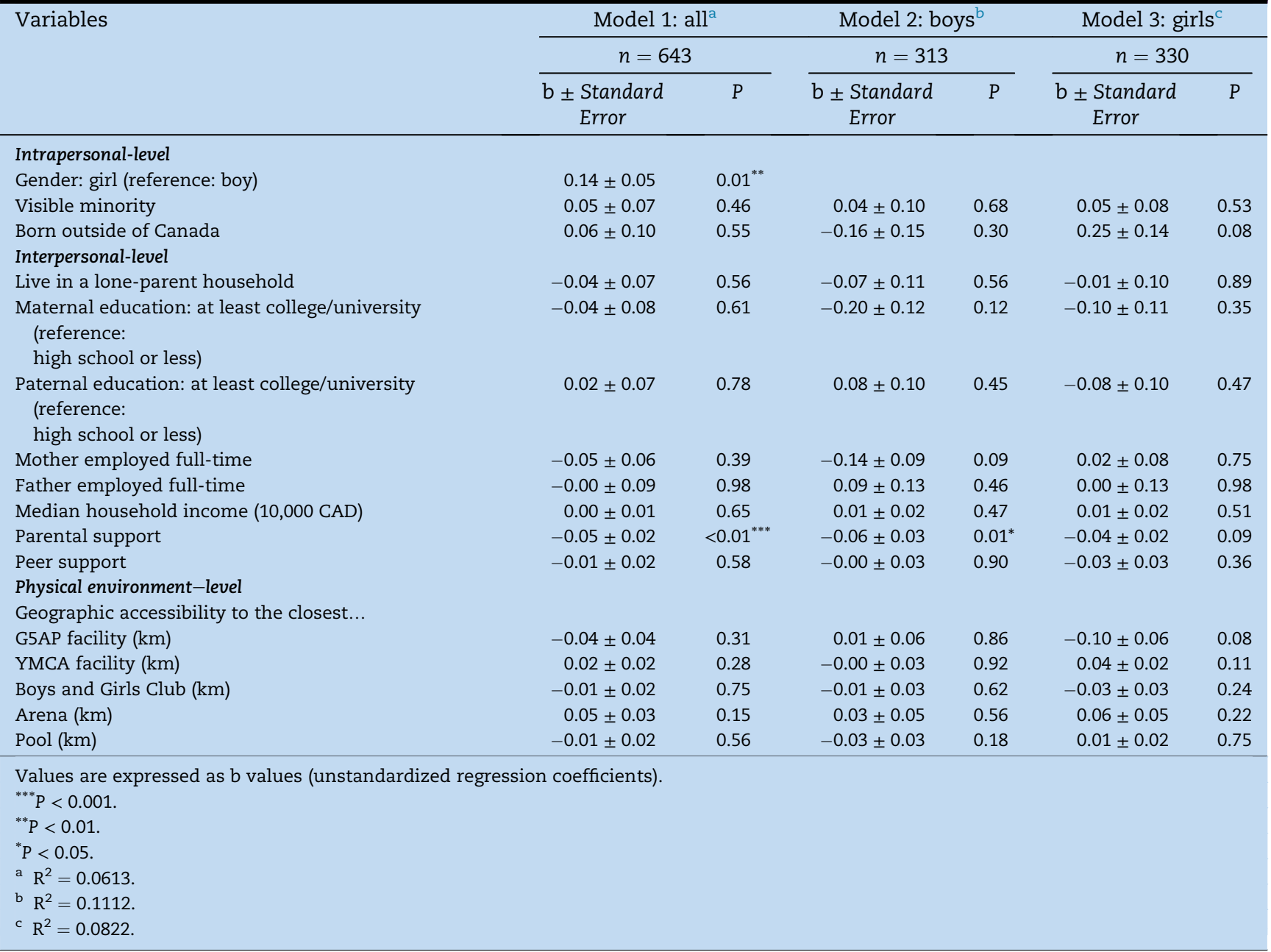


change in children's PA using a number of demographic variables and psychological variables reported by children and parents. The results showed that children's preferences for PA and frequency of parents transporting children to PA opportunities were associated with change in PA. NeumarkSztainer and colleagues ${ }^{38}$ found that the two strongest predictors of PA change were time constraints and support for PA from parents, peers, and teachers. Based on these findings, it is difficult to determine whether the variables used in the present study had no influence on children's PA, if important variables were left out, or whether the measures used were not precise enough to detect associations. It is evident that more research is needed to clarify the relationships between factors at different levels of influence to better understand the association with change in PA.

\section{Strengths and limitations}

A strength of this study is that it is designed to examine the effectiveness of a naturally occurring, population-based PA intervention. Using a longitudinal design comparing PA levels before the free G5AP intervention and at 6-month follow-up, this study found that children's PA significantly improved over time, especially among girls. Evidence from this research suggests that eliminating financial barriers to access PA opportunities is an effective strategy and should be considered for future interventions. Policy-makers have advocated for greater use of natural experiments as we have done here as they can provide direct evidence for the effectiveness of interventions in real-world settings. ${ }^{39}$

Despite its strong research design, the limitation of the study is the use of the PAQ-C to self-report PA levels of our young participants as the survey is limited by its subjectivity, recall, and social desirability bias. Although objective measures of PA would be preferable, using accelerometers would not be feasible in this large population-based study, and the PAQ-C has been identified as 'one of the very few self-reported instruments that has acceptable validity, reliability, and practicality for use in children. ${ }^{12}$ The high level of PA at baseline emphasizes the need to assess pass usage to determine which children were using the pass compared with those who did not to help identify other barriers that may influence a child's use of the program. Identifying barriers could help to develop more targeted approaches to reach children at greater risk of physical inactivity. ${ }^{40}$

\section{Conclusion}

As a large-scale study, the short-term findings from the G5AP intervention study offer greater insight into the potential of population-based interventions for increasing PA. The study findings reinforce the value of using natural experiments and a collaborative approach to assess population-based PA interventions. The findings also emphasize the need for additional research to determine what factors affect change in PA to inform future interventions. Above all, this study has direct implications for policy as the evidence is based on effectiveness in a real-world setting rather than conditions of a closed experiment. The results show the translation of PA research into practice and thus enable community stakeholders to make informed decisions about the effectiveness of the intervention.

\section{Author statements}

\section{Acknowledgments}

The authors would like to thank their ACT-i-Pass project partners from London's Child and Youth Network, Boys and Girls Club of London, YMCA of Western Ontario, the City of London Recreation Department, Thames Valley District School Board, London District Catholic School Board, and Montessori Academy of London. The authors are especially grateful for the leadership from Josh Archer (City of London), Nadine Harrison (BGCL), Chris Harvey (BGCL), David Inglis (Thames Valley District School Board), Tony Kyle (City of London), Sue McMahon (London District School Board), and the rest of the ACT-i-Pass working group for working with them to evaluate the ACT-i-Pass program. The authors would also thank field work leaders (Sabrina Sater, Christine Mitchell) and more than 20 additional undergraduate research assistants. Finally, the authors are grateful to the staff of participating schools and school boards, as well as the children and their parents who participated in the project.

\section{Ethical approval}

This study was conducted in accordance with the Declaration of Helsinki and the Canadian Tri-Council Policy Statement: Ethical Conduct for Research Involving Humans, and the protocol was approved by Western University's Non-Medical Research Ethics Board (NM103954) and the five local school boards.

\section{Funding}

The authors thank the funders of the ACT-i-Pass Program, which include the Canadian Cancer Society (grant \#703083) and Canadian Institutes of Health Research - Institute for Population and Public Health for project funding (CIHR grant \#322703 \& \#327369). Funding to support the implementation of the intervention was provided by London's Child and Youth Network and the Ontario Sport and Recreation Community Fund. Finally, funding for trainees was provided by Children's Health Research Institute and Children's Health Foundation.

\section{Competing interests}

None declared.

\section{R E F E R E N C E S}

1. Colley R, Carson V, Garriguet D, Janssen I, Roberts K, Tremblay M. Physical activity of Canadian children and youth, 2007 to 2015. Health Rep 2017;28(10):8-16.

2. Tremblay MS, Barnes JD, González SA, Katzmarzyk PT, Onywera VO, Reilly JJ, et al. Global matrix 2.0: report card grades on the physical activity of children and youth 
comparing 38 countries. J Phys Act Health [Internet] 2016 Nov;13(11 Suppl 2). S343-66. Available from: http://www. ncbi.nlm.nih.gov/pubmed/27848745.

3. Metcalf B, Henley W, Wilkin T. Effectiveness of intervention on physical activity of children: systematic review and metaanalysis of controlled trials with objectively measured outcomes (EarlyBird 54). BMJ 2012;345(4). e5888-e5888.

4. Russ LB, Webster CA, Beets MW, Phillips DS. Systematic review and meta-analysis of multi-component interventions through schools to increase physical activity. J Phys Act Health [Internet] 2015 Oct;12(10):1436-46. Available from: http:// journals.humankinetics.com/doi/10.1123/jpah.2014-0244.

5. van Sluijs EMF, McMinn AM, Griffin SJ. Effectiveness of interventions to promote physical activity in children and adolescents: systematic review of controlled trials. BMJ [Internet] 2007 Oct 6;335(7622):703. Available from: http:// www.bmj.com/lookup/doi/10.1136/bmj.39320.843947.BE.

6. Pate RR, Trost SG, Mullis R, Sallis JF, Wechsler H, Brown DR. Community interventions to promote proper nutrition and physical activity among youth. Prev Med (Baltim) [Internet] 2000 Aug;31(2):S138-49. Available from: http://linkinghub.elsevier. com/retrieve/pii/S0091743500906327.

7. Sallis J, Owen N. Ecological models of health behavior. In: Glanz B, Rimer K, Viswanath K, editors. Health behavior and health education. 5th ed. San Fransisco, CA: Jossey-Bass; 2015. p. 43-64.

8. Haggis C, Sims-Gould J, Winters M, Gutteridge K, McKay HA. Sustained impact of community-based physical activity interventions: key elements for success. BMC Public Health [Internet] 2013 Dec 27;13(1):892. Available from: http:// bmcpublichealth.biomedcentral.com/articles/10.1186/14712458-13-892.

9. Sallis JF, Glanz K. The role of built environments in physical activity, eating, and obesity in childhood. Futur Child [Internet] 2006;16(1):89-108. Available from: www. futureofchildren.org.

10. Gilliland JA, Clark AF, Tucker P, Prapavessis H, Avison W, Wilk P. The ACT-i-Pass study protocol: How does free access to recreation opportunities impact children's physical activity levels? BMC Public Health 2015;15:1286. Available from: https:// doi:10.1186/s12889-015-2637-x.

11. Clark AF, Wilk P, Mitchell CA, Smith C, Archer J, Gilliland J A. Examining how neighborhood socioeconomic status, geographic accessibility, and informational accessibility influence the uptake of a free population-level physical activity intervention for children. Am J Heal Promot 2018;32(2):315-24. Available from: https://doi:10.1177/ 0890117117718433.

12. Crocker PR, Bailey DA, Faulkner RA, Kowalski KC, McGrath R. Measuring general levels of physical activity: preliminary evidence for the Physical Activity Questionnaire for Older Children. Med Sci Sports Exerc [Internet] 1997 Oct;29(10):1344-9. Available from: http://www.ncbi.nlm.nih.gov/pubmed/ 9346166.

13. Janz KF, Lutuchy EM, Wenthe P, Levy SM. Measuring activity in children and adolescents using self-report. Med Sci Sport Exerc [Internet] 2008 Apr;40(4):767-72. Available from: https:// insights.ovid.com/crossref?an=00005768-200804000-00025.

14. Mitchell CA, Clark AF, Gilliland JA. Built environment influences of children's physical activity: examining differences by neighbourhood size and sex. Int J Environ Res Public Health [Internet] 2016 Jan 15;13(1):130 [cited 2017 Feb 27], http://www.mdpi.com/1660-4601/13/1/130. Available from:

15. Singhammer J, Ried-Larsen M, Møller NC, Lund-Kristensen $P$, Froberg K, Andersen LB. Single parent status and children's objectively measured level of physical activity. Sport Med Open [Internet] 2015 Dec 2;1(1):10. Available from: http://www. sportsmedicine-open.com/content/1/1/10.
16. Brodersen NH, Steptoe A, Boniface DR, Wardle J, Hillsdon M. Trends in physical activity and sedentary behaviour in adolescence: ethnic and socioeconomic differences. $\mathrm{Br} J$ Sports Med [Internet] 2007 Mar 1;41(3). 140-4. Available from: http://bjsm.bmj.com/cgi/doi/10.1136/bjsm. 2006.031138.

17. Trost SG, Pate RR, Sallis JF, Freedson PS, Taylor WC, Dowda M, et al. Age and gender differences in objectively measured physical activity in youth. Med Sci Sport Exerc 2002;34(2):350-5.

18. Singh GK, Yu SM, Siahpush M, Kogan MD. High levels of physical inactivity and sedentary behaviors among US immigrant children and adolescents. Arch Pediatr Adolesc Med [Internet] 2008 Aug;162(8) [cited 2016 Jul 6], http://www. ncbi.nlm.nih.gov/pubmed/18678808. 756-63. Available from:.

19. Statistics Canada. Dissemination area (DA) [Internet]. Census dictionary. 2015 [cited 2019 Jan 15]. Available from: https:// www12.statcan.gc.ca/census-recensement/2011/ref/dict/ geo021-eng.cfm.

20. Mustard CA, Derksen S, Berthelot J-M, Wolfson M. Assessing ecologic proxies for household income: a comparison of household and neighbourhood level income measures in the study of population health status. Health Place [Internet] 1999 Jun;5(2):157-71. Available from: http://linkinghub.elsevier. com/retrieve/pii/S1353829299000088.

21. Wilk P, Clark AF, Maltby A, Tucker P, Gilliland JA. Exploring the effect of parental influence on children's physical activity: the mediating role of children's perceptions of parental support. Prev Med (Baltim) 2018;106:79-85.

22. Sallis JF, Taylor WC, Dowda M, Freedson PS, Pate RR. Correlates of vigorous physical activity for children in grades 1 through 12: comparing parent-reported and objectively measured physical activity. Pediatr Exerc Sci [Internet] 2002 Feb;14(1):30-44. Available from: http://journals. humankinetics.com/doi/10.1123/pes.14.1.30.

23. Prochaska JJ, Rodgers MW, Sallis JF. Association of parent and peer support with adolescent physical activity. Res Q Exerc Sport [Internet] 2002 Jun;73(2). 206-10. Available from: http:// www.tandfonline.com/doi/abs/10.1080/02701367.2002. 10609010.

24. Wilk P, Clark AF, Maltby A, Smith C, Tucker P, Gilliland JA. Examining individual, interpersonal, and environmental influences on children's physical activity levels. SSM - Popul Heal [Internet] 2018 Apr;4:76-85. Available from: http:// linkinghub.elsevier.com/retrieve/pii/S2352827317301386.

25. Kowalski KC, Crocker PRE, Faulkner RA. Validation of the physical activity Questionnaire for older children. Pediatr Exerc Sci 1997;9:174-86.

26. Benítez-Porres J, López-Fernández I, Raya JF, Álvarez Carnero S, Alvero-Cruz JR, Álvarez Carnero E. Reliability and validity of the PAQ-C Questionnaire to assess physical activity in children. J Sch Health [Internet] 2016 Sep;86(9):677-85. Available from:

27. Voss C, Ogunleye AA, Sandercock GR. Physical Activity Questionnaire for children and adolescents: English norms and cut-off points. Pediatr Int [Internet] 2013 Aug;55(4):498-507. Available from:.

28. de Meij JSB, Chinapaw MJM, van Stralen MM, van der Wal MF, van Dieren L, van Mechelen W. Effectiveness of JUMP-in, a Dutch primary school-based community intervention aimed at the promotion of physical activity. Br J Sports Med [Internet] 2011 Oct;45(13):1052-7. Available from: http://www.ncbi.nlm. nih.gov/pubmed/21112875.

29. Martínez-Vizcaíno V, Sánchez-López M, Notario-Pacheco B, Salcedo-Aguilar F, Solera-Martínez M, Franquelo-Morales P, et al. Gender differences on effectiveness of a school-based physical activity intervention for reducing cardiometabolic risk: a cluster randomized trial. Int J Behav Nutr Phys Act 
[Internet] 2014 Dec 10;11(1):154. Available from: http://ijbnpa. biomedcentral.com/articles/10.1186/s12966-014-0154-4.

30. Mota J, Esculcas C. Leisure-time physical activity behavior: structured and unstructured choices according to sex, age, and level of physical activity. Int J Behav Med [Internet] 2002 Jun;9(2):111-21. Available from: http://link.springer.com/10. 1207/S15327558IJBM0902_03.

31. Lorenc T, Petticrew M, Welch V, Tugwell P. What types of interventions generate inequalities? Evidence from systematic reviews: table 1. J Epidemiol Community Health [Internet] 2013 Feb;67(2). 190-3. Available from: http://jech. bmj.com/lookup/doi/10.1136/jech-2012-201257.

32. Azar D, Naughton GA, Joseph CW. Physical activity and social connectedness in single-parent families. Leis Stud [Internet] 2009 Jul;28(3):349-58. Available from: http://www. tandfonline.com/doi/abs/10.1080/02614360903046656.

33. Quarmby T, Dagkas S. Children's engagement in leisure time physical activity: exploring family structure as a determinant. Leis Stud [Internet] 2010 Jan;29(1):53-66. Available from: http:// www.tandfonline.com/doi/abs/10.1080/02614360903242560.

34. Beets MW, Vogel R, Forlaw L, Pitetti KH, Cardinal BJ. Social support and youth physical activity: the role of provider and type. Am J Health Behav [Internet] 2006;30(3):278-89. Available from: http://www.ingentaconnect.com/content/png/ajhb/ 2006/00000030/00000003/art00006.

35. Trost SG, Loprinzi PD. Parental influences on physical activity behavior in children and adolescents: a brief review. Am J
Lifestyle Med [Internet] 2011 Mar 7;5(2):171-81. Available from: http://journals.sagepub.com/doi/10.1177/1559827610387236.

36. Welk GJ, Wood K, Morss G. Parental influences on physical activity in children: an exploration of potential mechanisms. Pediatr Exerc Sci [Internet] 2003 Feb;15(1):19-33. Available from: http://journals.humankinetics.com/doi/10.1123/pes.15.1.19.

37. Sallis JF, Alcaraz JE, McKenzie TL, Hovell MF. Predictors of change in children's physical activity over 20 months. Am J Prev Med [Internet 1999 Apr;16(3):222-9. Available from: http:// linkinghub.elsevier.com/retrieve/pii/S0749379798001548.

38. Neumark-Sztainer D, Story M, Hannan PJ, Tharp T, Rex J. Factors associated with changes in physical activity. Arch Pediatr Adolesc Med [Internet] 2003 Aug 1;157(8):803. Available from: http://archpedi.jamanetwork.com/article.aspx?doi=10. 1001/archpedi.157.8.803.

39. Craig P, Cooper C, Gunnell D, Haw S, Lawson K, Macintyre S, et al. Using natural experiments to evaluate population health interventions: new Medical Research Council guidance. J Epidemiol Community Health [Internet] 2012 Dec;66(12):1182-6. Available from: http://jech.bmj.com/ lookup/doi/10.1136/jech-2011-200375.

40. Clark AF, Campbell J, Tucker P, Wilk P, Gilliland J A. If you make it free, will they come? Using a physical activity accessibility model to understand the use of a free children's recreation pass. J Phys Act Health 2019;16(7):493-503. Available from: https://journals.humankinetics.com/view/ journals/jpah/16/7/article-p493.xml. 